\title{
Effect of physicochemical parameters on magnetic treatment of water
}

\author{
Redouane Mghaiouini ${ }^{1,2^{*}}$, Mohammed Salah $^{3}$, Mohamed Monkad ${ }^{2}$ and Abdeslam El Bouari ${ }^{1}$ \\ ${ }^{1}$ Department of Chemistry, Physical Chemistry Laboratory Applied Materials, Faculty of Sciences- \\ Ben M'sik, Hassan II University, Casablanca Morocco. \\ ${ }^{2}$ Department of Physics, Condensed Matter Laboratory, Faculty of Sciences, Chouaib \\ Doukkali University, Eljadida Morocco. \\ ${ }^{3}$ Department of Chemistry, Molecular Modeling and Spectroscopy Research Team, Faculty of \\ Sciences, Chouaïb Doukkali University, El Jadida, Morocco.
}

\begin{abstract}
The main objective of this work is to offer a new knowledge of the water magnetism phenomenon, indeed the present study focused on the search of the most decisive parameters, which influence the process of magnetization of water. The main parameters studied in the present paper are the temperature, the salinity, the $\mathrm{pH}$ and the linear flow speed of the water. The increases of temperature, water velocity or salinity extend the magnetization time, however the variation of $\mathrm{pH}$ does not have any influence. The outcomes of this work will be very helpful for engineers in agriculture and other industrial fields to a better use of magnetized water (MW).
\end{abstract}

\section{Introduction}

The properties of water and their changes under the action of a magnetic field were approved by many studies in literature [1-5]. Indeed, water treated by a magnetic field, undergo a lot of changes in its physical properties, optics, electromagnetism, thermodynamics and mechanics, compared with those of pure water [6-12]. Xiao Feng Pang et al. [13] have studied the influences of magnetic field on physical properties of water, including soaking effect, electric conductivity, specific heat, surface tension force, and refraction index. They found that the magnetic fields reduce the specific heat of water, increase the soaking degree and hydrophobicity of water to materials, and depress its surface tension force and increase refractive index and electric conductivity of water relative to those of pure water.

According to them, these changes are caused by the variation of microscopic structures and distribution of water molecules under the action of a magnetic field. The physical water treatment in the magnetic field has emerged as an alternative solution in place of the chemical water treatment and other conventional process. Thus, water treated by a magnetic field has extensive applications in many fields as biology [14], electrochemistry [15], building construction [16-18], agriculture [19-20] and other fields [21-27]. In the same 
spirit, the present work, focuses mostly on the effect of electromagnetic field on the water, and offer more knowledge of magnetism phenomenon of this liquid. Indeed, the present paper focuses on the search of the most decisive parameters, which influence the process of magnetization of water using a special magnetic device, which generates a low electromagnetic field of $40 \mathrm{nT}$. The outcomes of this work will be very helpful for engineers in agriculture and in other industrial fields.

\section{Experimental background}

\subsection{Materials description}

The aqua-4D Magnetic water treatment is a physical process based on quantum mechanics and electromagnetism [28]. To detect the action of the electromagnetic flux density on water, a specific equipment was realized in the laboratory. It consists of an apparatus that generates the electromagnetic field, a pump, sensors connected to a computer to follow the magnetization of the water (Figure 1). The experiment consists of pumping the water from one tank to the other by passing it through the electromagnetic apparatus.

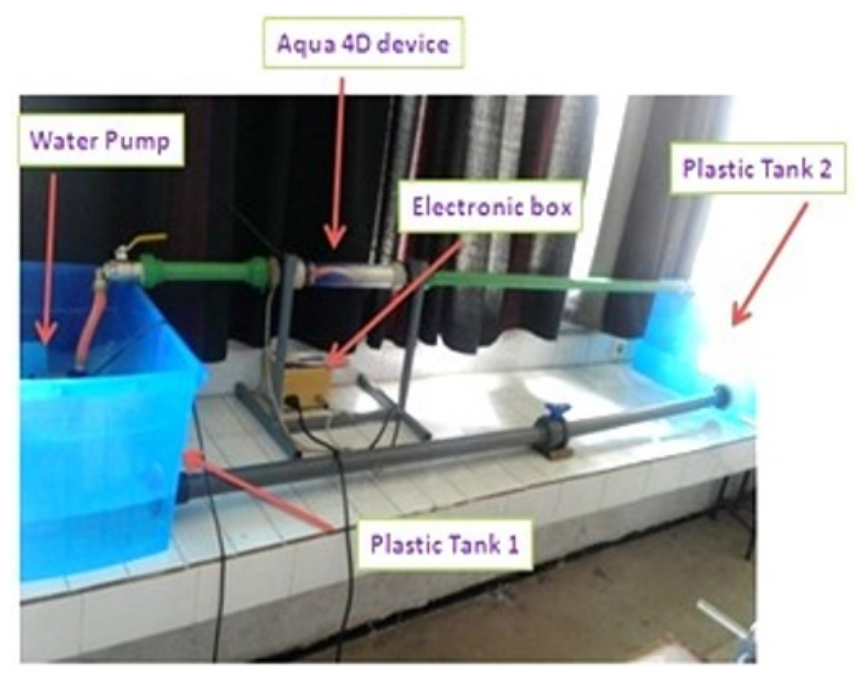

Fig. 1. Equipment of aqua-4D and Electromagnetic field generator.

The figure 2shows the method of heating the magnetized water and tap water to do a comparative study by visualizing the electromagnetic field at equilibrium, during heating and cooling of both types of water. The monitoring of the electromagnetic field was done by the Kobra software. The data were automatically recorded. 
(A)

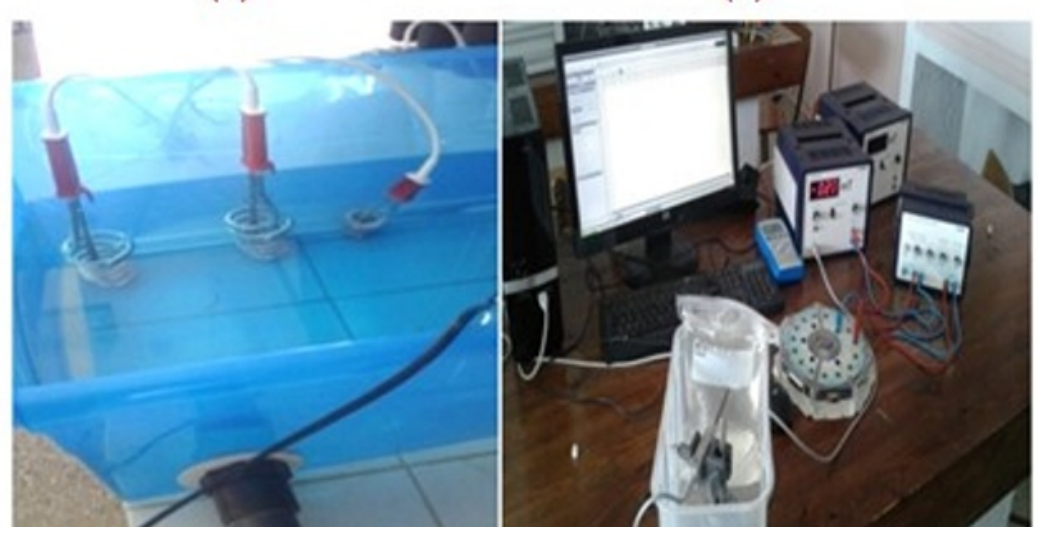

Fig. 2. (A)Method of heating of MW and measurement of electromagnetic. (B) Field intensity as a function of time.

\subsection{The rearrangement of molecules $\mathrm{H}_{2} \mathrm{O}$}

The figure 3 depicts the main elements of water, which are hydrogen bond (Figure 3a) and dipole moment (Figure 3b), ensuring cohesion between water clusters without electromagnetic field and in the existence of the magnetic field flux. They respond to the influence of the energies coming from outside.

(A)

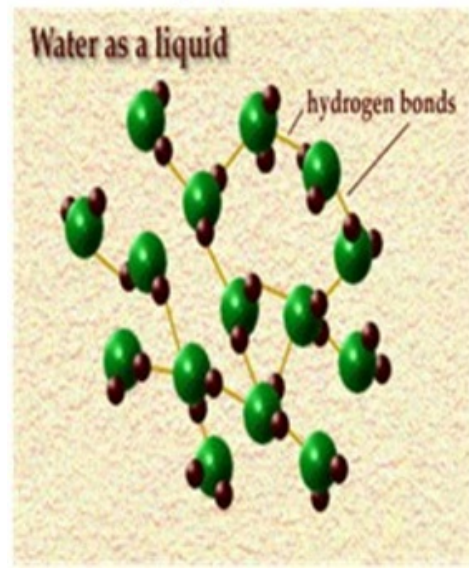

(B)

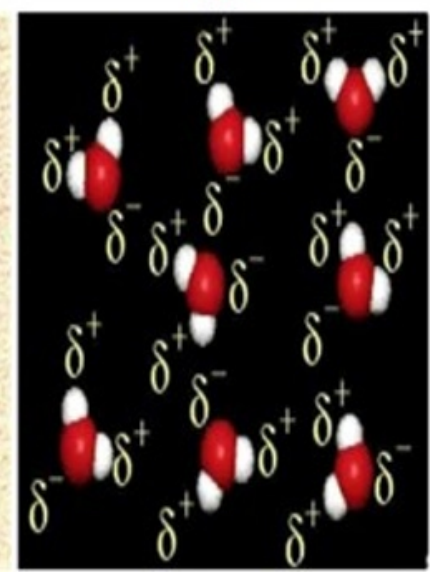

Fig.3. Water as a liquid without (Right) and with electromagnetic field (Left).

\section{Results and discussion}

\section{1 magnetization phenomenon of water}

In order to check the capacity of storing water for the electromagnetic energy, we have investigated the evolution of the magnetic field received, during treatment by the electromagnetic field, generated by the Aqua-4D device (Figure4). 
The linear regression of the fluctuations of the magnetic field received by the tap water shows a decrease in a non-zero value $(0.0075 \mathrm{mT})$ after eight hours $(28800 \mathrm{~s})$, which shows the magnetization phenomenon of water. Consequently, the water is a substance having the ability to store electromagnetic energy.

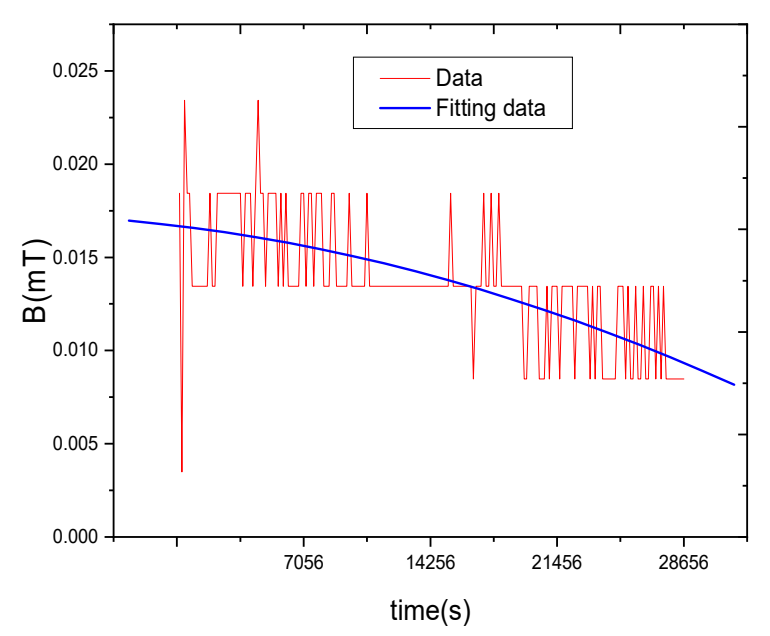

Fig. 4. Monitoring of fluctuations in the static magnetic field of magnetized water

During the $15 \mathrm{~h}$ of electromagnetic treatment, the recorded magnetic field fluctuations, are relatively low $(B \max =0.0230 \mathrm{mT}$ and $B \min =-0.025 \mathrm{mT})$ with an average value of $0.0015 \mathrm{mT}$. This variation is slightly greater than the value measured before the application of the electromagnetic field. These assessments of the flux density of the magnetic field allowed us to monitor possible fluctuations in this field after the exposure of both types of water (magnetized water (MW) and tap water (TW)) to the electromagnetic field. The experiments indicate that tap water has indeed become magnetized after the treatment by the flux density of the magnetic field generated by the aqua-4D device. The evolution of the static magnetic field after the electromagnetic treatment generated by the aqua-4D device was followed. The experimental results show that during the $15 \mathrm{~h}$ of electromagnetic treatment, the recorded magnetic field fluctuations are relatively low $(\mathrm{Bmax}=0.023 \mathrm{mT}$ and $\mathrm{Bmin}=0.008 \mathrm{mT}$ ) worth an average of $0.0155 \mathrm{mT}$ for magnetic water, whereas for tap water the obtained values are $B \max =0.0185 \mathrm{mT}$ and $\mathrm{Bmin}=0.005 \mathrm{mT}$ with a Bavgof $0.01175 \mathrm{mT}$. The measurements of magnetic field allow to monitor the possible fluctuations of this field after the exposure of the samples to the electromagnetic field.

\subsection{Effect of temperature on EMF intensity and magnetization time}

According to literature [29], the thermal agitation of water causes a rotational motion of hydrogens (positively charged) around the oxygen nucleus (negatively charged), which forms an electric current with a short duration generating a Lorentz force in a uniform static magnetic field which influence on chemical and physical properties of water. Indeed, for a better concrete of the effecting of temperature on the magnetization water phenomenon, we have proceeded to a variation of the temperature and observe the influence of this variation on the time of magnetization of water.

The figures 5 illustrate the influence of temperature on the effect of magnetization by the electromagnetic field generated by the Aqua 4D apparatus. According to the previous figure, the water passes through an electromagnetic field, becomes magnetized water 
(MW). The time of magnetization at $26.5^{\circ} \mathrm{C}, 40^{\circ} \mathrm{C}$ are $15 \mathrm{~h}, 12 \mathrm{~h}$ respectively, so there is a difference of $3 \mathrm{~h}$ as TM between the two conditions of temperature. Consequently, the increase of temperature decrease the time of magnetization of water. Concerning the relation between the intensity of magnetic field and temperature we have observed that the Bavg at $26.5^{\circ} \mathrm{C}$ is equal to $0.020 \mathrm{mT}$, but at $40^{\circ} \mathrm{C}$ the value of Bavg does not exceed a value of $0.002 \mathrm{mT}$. So, the increase of temperature decreases dramatically the intensity of magnetic field. This experimental observation is in conformity with the fundamental laws of electromagnetisms magnetic moments. The thermal agitation of water molecules causes a disorder by Brownian motion and the disappearance of the magnetic order.
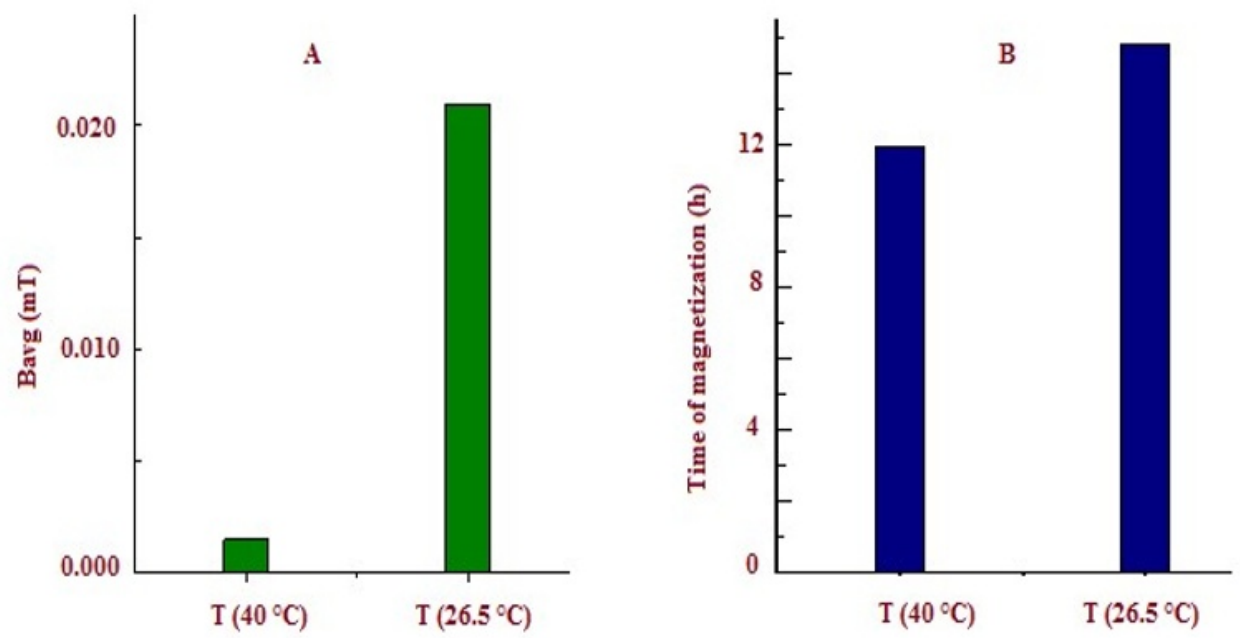

Fig.5. (A) Intensity of the average magnetic field of the water according to temperature. (B) Magnetization time as a function of water temperature.

\subsection{Effect of Salinity on EMF intensity and magnetization time}

The water is diamagnetic, in the presence of a magnet; the water's diamagnetism will repel the magnet. When salt is added, it increases the intensity of the water's magnetic field. So, we have tried to study this phenomenon. Indeed, we proceed to a variation of the salinity at a fixed temperature of $26.5^{\circ} \mathrm{C}$ leaving the conductivity of the water increases during the action of electromagnetic field. The profile of variation of the electromagnetic field as a function of time in the case of salty water in comparison with that of tap water indicates that the electromagnetic field is affected by the salinity. The impact of salinity on the intensity of EMF is very weak (Figure 6), indeed the intensity of EMF at salinity $(0.048 \mathrm{~g} / \mathrm{l})$ is $\mathrm{B}_{\mathrm{avg}}=0.020 \mathrm{mT}$, the increase of salinity by $35.952 \mathrm{~g} / \mathrm{l}$ caused a slight increase of intensity of magnetic field (IMF) by $0.0025 \mathrm{mT}$ so, the impact of salinity on IMF is very weak. Concerning the time of magnetization (TM) of water, we observe the decrease of TM with salinity, therefore at salinity of $0.048 \mathrm{~g} / \mathrm{l}$, the time of magnetization is equal to $11.5 \mathrm{~h}$, but at salinity of $36 \mathrm{~g} / \mathrm{l}$ we obtained $15 \mathrm{~h}$ as TM, so the increase of salinity extended the TM (Figure 6). Thus, the factor of salinity promotes the magnetization of water by extending the time of magnetization of water with a weak impact on intensity of magnetic field. 
A

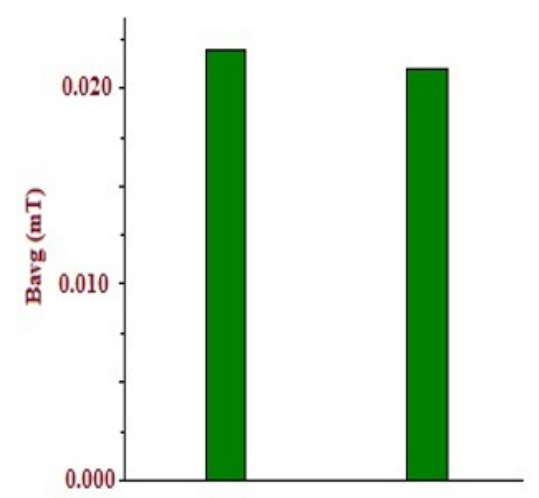

B

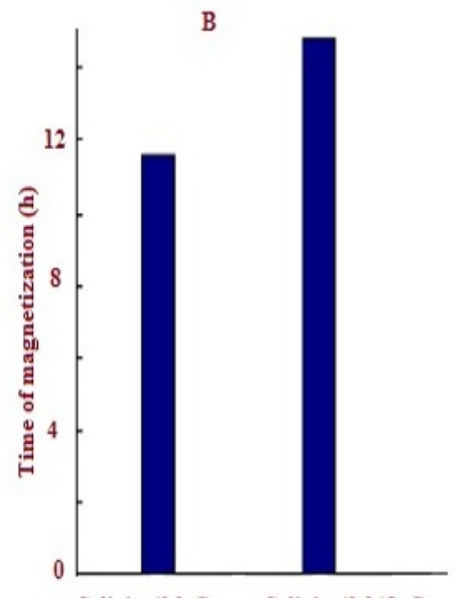

Fig.6. (A) Intensity of the average magnetic field of water as a function of salinity. (B) Variation of magnetization time according to the salinity of water.

\subsection{Effect of pH on EMF intensity and magnetization time}

In literature [30], some works have studied the effect of magnetic field on water characteristics, specially the variation in the $\mathrm{pH}$ on treated and no treated water. In our case we have focused on the effect of $\mathrm{pH}$ on EMF intensity and magnetization time. The results are depicted at figure 7.
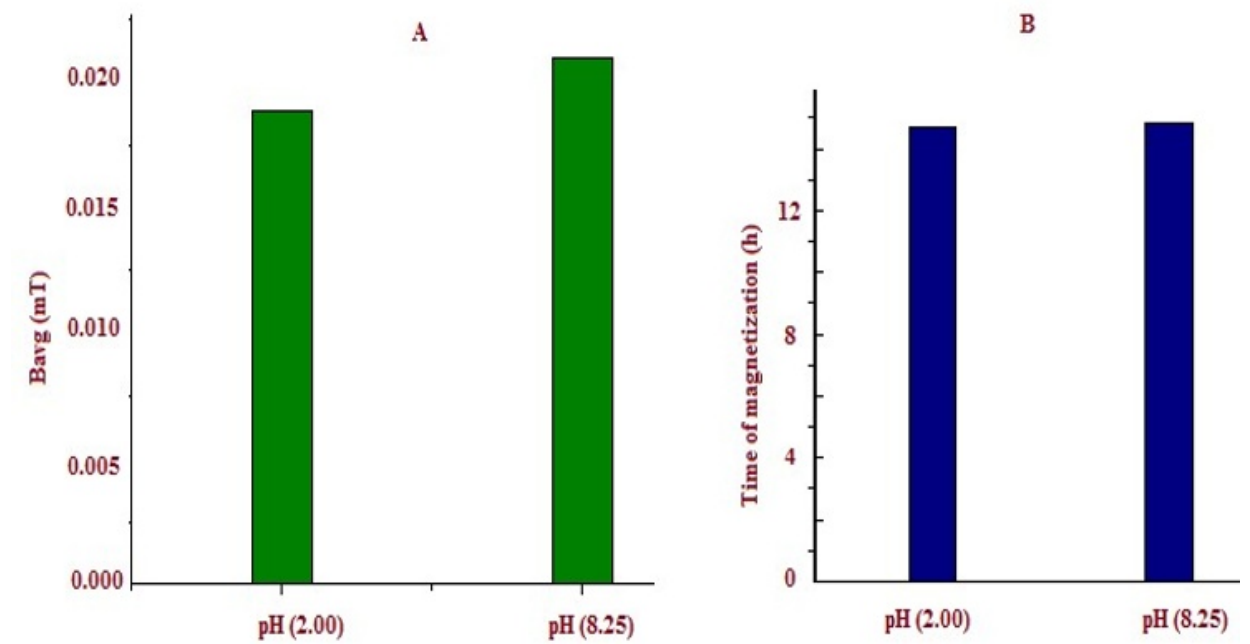

Fig.7. (A)Intensity of the average magnetic field of water according to $\mathrm{pH}$.

(B)Magnetization time and water $\mathrm{pH}$.

According to figure 7 , the intensity of magnetic field at $\mathrm{pH}=2$ (very acidic environment) the intensity of magnetic field is equal to $0.018 \mathrm{mT}$. The increase of $\mathrm{pH}$ from acidic to basic $\mathrm{pH}=8.25$, increases the intensity of magnetic field by $0.002 \mathrm{mT}$, so the impact of variation of $\mathrm{pH}$ on IMF is weak. in other side, concerning the impact of $\mathrm{pH}$ on the time of magnetization of water we observe the following. The time of magnetization at $\mathrm{pH}=2.00$ is $15 \mathrm{~h}$, but at $\mathrm{pH}=8.25$ we obtained a value of $15.30 \mathrm{~h}$ as time of magnetization, so the 
influence of the $\mathrm{pH}$ at time of magnetization is very slight.

\subsection{Effect of water velocity on EMF and magnetization time}

Among the most parameters cited in the studies of water magnetization, we found the velocity parameter. For example, F. Alimi et al. [31] have tested the variation of the efficiency of the magnetic treatment when the flow velocity was changed. In our case we have studied the effect of water velocity on EMF and magnetization time. The results are depicted in figure8.
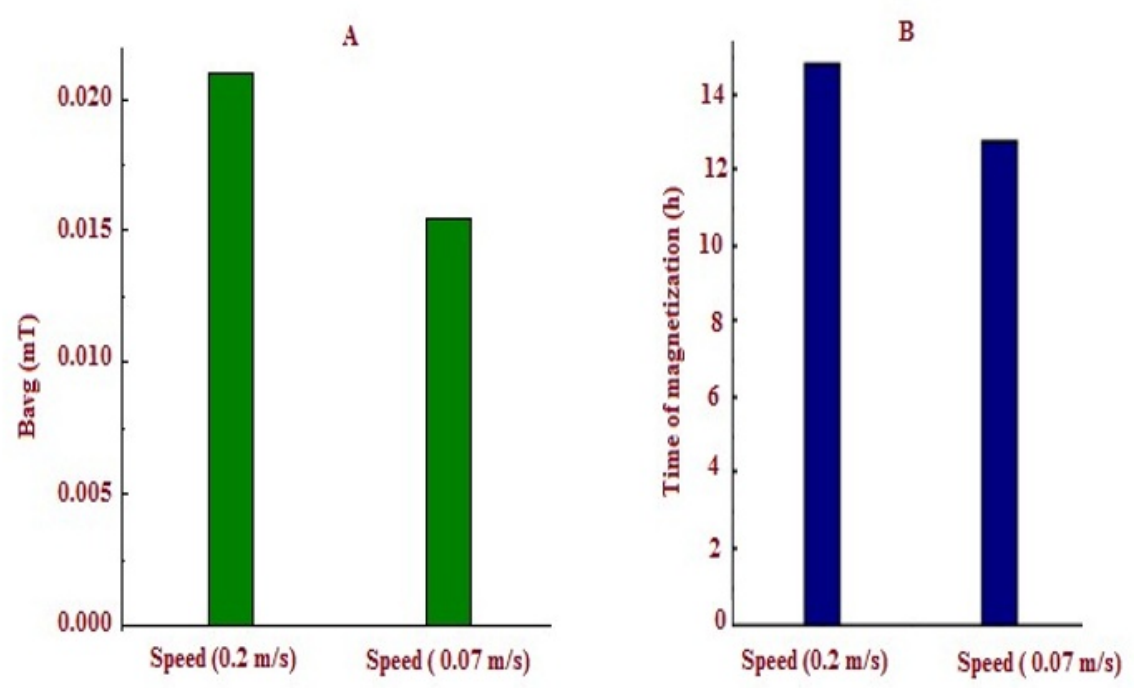

Fig. 8. (A) Intensity of the average magnetic field of water as a function of rate flow.(B) Magnetization according of both flow rates of tap water

According to our results we have observed the following. At $0.2 \mathrm{~m} / \mathrm{s}$ the intensity of EMF is $0.0025 \mathrm{mT}$ but at $0.07 \mathrm{~m} / \mathrm{s}$ we obtained $0.0016 \mathrm{mT}$, consequently the decrease of velocity of water by $0.193 \mathrm{~m} / \mathrm{s}$ decreases the intensity of magnetic field from $0.025 \mathrm{mT}$ at $\mathrm{V}=0.2$ $\mathrm{m} / \mathrm{s}$ to $0.0152 \mathrm{mT}$ at $0.07 \mathrm{~m} / \mathrm{s}$, consequently, the water velocity influenced the intensity of magnetic field of water. Concerning the impact of water velocity on magnetization time we observe that the TM is equal to $15 \mathrm{~h}$ at $0.2 \mathrm{~m} / \mathrm{s}$ but at $0.07 \mathrm{~m} / \mathrm{s}$ we found $12 \mathrm{~h}$ only as time of magnetization, so the velocity of water affects its magnetic field and its time of magnetization. The variation of water velocity by $0.13 \mathrm{~m} / \mathrm{s}$ caused an increase of $0.004 \mathrm{mT}$ of IMF and extended the TM by 2 hours.

\section{Conclusion}

According to the results of the present work, we can conclude the following: The water owns the ability to store the electromagnetic energy. The important factors which increase the performance of electromagnetic devices are the salinity, the speed of water and temperature. The increase of salinity causes a variation of the intensity of magnetic field and extends the magnetization time by 3 hours. The thermal agitation of water declines the intensity of the magnetic field and extends the magnetization time by 3 hours. The variation of $\mathrm{pH}$ has a slight effect on the intensity of magnetic field but not on the magnetism time. The variation in the water velocity affects the magnetic field of water and 
the time of magnetization. The variation of water velocity by $0.13 \mathrm{~m} / \mathrm{s}$ caused an increase of $0.004 \mathrm{mT}$ and extended the time of magnetization by 2 hours.

\section{Acknowledgements}

We would like to thank company planet horizons technologies SA (Switzerland), to provide assistance in Aqua-4D electromagnetic processing equipment.

\section{References}

1. M.C. Amiri, A.A. Dadkhah, Colloids Surf. Physicochem. Eng. Asp. 278, 252 (2006)

2.J.S. Baker, S.J. Judd, Water Res30,(1996)

https://doi.org/10.1016/0043-1354(95)00184-0

3. A. Bubnov, V. Novotná, V. Hamplová, M. Kašpar, M. Glogarová, J. Mol. Struct. 892, 151 (2008)

4. R. Cai, H. Yang, J. He, W. Zhu, J. Mol. Struct. 938, 15 (2009)

5. A.C.Cefalas, E. Sarantopoulou, Z. Kollia, C. Riziotis, G. Dražic, S. Kobe, J. Stražišar,A.Meden,J.Comput.Theor.Nanosci(2010).https://doi.org/info:doi/10.1166/jctn.201 0.1544

6. K.T. Chang, C.I. Weng, J. Appl. Phys. 100, (2006) 043917.https://doi.org/10.1063/ 1.233597

7. M.C. Chang, C.Y. Tai, Chem. Eng. J. 164, 1 (2010)

8. E. Chibowski, L. Hołysz, , A. Szcześ, Water Res. 37, 4685 (2003)

9. E. Chibowski,A. Szcześ, Chemosphere 203, 54(2018)

10. P. X. Feng, D. Bo, Sci China Ser G-PhysMechAstron, 51, 1621(2008)

11. L. Holysz, A. Szczes, E. Chibowski J. Colloid Interface Sci,316,996 (2007)

12. K.X. Zhou, G.W. Lu, Q.C. Zhou, J.H. Song, S.T. Jiang, and H. R. Xia J Appl Phys, 88, 1802 (2000); https://doi.org/10.1063/1.1305324

13. X.F. Pang, B. Deng and B. Tang,ModPhys Lett B, 26, (2012) DOI:10.1142/ S0217984912500698.

14. M. Molouk, K. Alkhazan and A.A. Nasser Saddiq, J Evolution Biol

2, 7(2010)

15. G.B.chyus, A. Ruchinskene, and V. Deninis Protection of Metals, 39, 443(2003)

16. N. Su, C.F. Wu.Cem. Concr. Compos,25,681(2003)

17. H.Wei,Y.Wang, Jianjun Luo,Constr Build Mater 91-100.

(2017)

18. I.J. lin and J. Yotvat, J. Magn. Magn. Mater,83, (1990)

19. J. Bogatine, Environ. Sci. Technol., 33, 1280(1999)

20. R.Noran,U.Shani and I.Lin, Magn Electr Separ vol.7, pp.109-122(1996)

21.R.Mghaiouini,Ecol. Eng,21, 245 (2020) doi:10.12911/22998993/119816.

22. R. Mghaiouini, A.Graich, A.Elaoud, T. Garmim, et al. Indian J Sci Technol, 13, 1172 (2020)

23. R. Mghaiouini, A. Elmelouky, and A. Elaoud, Int. j. adv. appl. sci, 7,91(2020).

24. R.Mghaiouini,A.Elmelouky,A.El Moznine, M. Monkade, A. El Bouari MedJChem 10, 1 (2020)

25. R. Mghaiouini, N.Benzbiria, M.E. Belghiti, H.E. Belghiti, M. Monkade, A.El bouari. (2020),matpr.https://doi.org/.matpr.2020.04.518

26.R. Mghaiouini, A. Elaouad, H Taimoury, I. Sabir et al. Int. J. Curr. Eng. Technol10,1(2020)

27.R.Mghaiouini,A. Elaoud,T. Garmim , M.E. Belghiti et alInt. j. adv. appl. sci(2020),DOI: https://doi.org/10.14741/ijcet/v.10.1.4 
28. O. Toshiaki ,T. Hozumi, J. Appl. Phys., 106,1(2009)

29. H.B. Amor, A. Elaoud, M. Hozayn, Asian Res. J. Agric, 8,1 (2018)

30. F. Alimi, M. Tlili, C.Gabrielli, M. Georges, M.B. Amor,Water Res, 40, 1 (2006) 